\title{
Design of a prototype D-STATCOM using DSP controller for voltage sag mitigation
}

\begin{abstract}
This paper presents the design of a prototype distribution static compensator (D-STATCOM) for load compensation in an unbalanced distribution system. The D-STATCOM is intended to replace the widely used static VAr compensator (SVC). The compensation scheme of the D-STATCOM is derived using the symmetrical component method. In this work, the 12pulse D-STATCOM configuration with IGBT has been designed and the graphic based models of the D-STATCOM have been developed using the PSCAD/EMTDC electromagnetic transient simulation program. Accordingly, simulation is first carried out to illustrate the use of D-STATCOM in mitigating voltage sag in a distribution system. The DSTATCOM has been developed using DSP controller to achieve excellent overall performance. Simulation results prove that the D-STATCOM is capable of mitigating voltage sag by controlling PWM of the system using DSP board.
\end{abstract}

Keyword: D-STATCOM; Load compensation; Voltage sag 